\title{
Cellular Senescence and Inflammation: A Noteworthy Link
}

\author{
George Tsirpanlis
}

Department of Nephrology, General Hospital of Athens, Athens, Greece

\section{Key Words}

Interleukin-6 • Atherosclerosis · Chronic kidney disease •

Telomeres

\begin{abstract}
Although cellular senescence and inflammation have been indirectly associated, a direct connection was absent until recently, when two studies proved that senescence at a cellular level is directly linked to an interleukin (IL)-dependent inflammatory network. IL-6 and IL-8, two well-known proinflammatory cytokines, seem to play a central role in premature cellular senescence induction. Activation of the abovementioned molecules and their receptors is necessary for the initiation of senescence while their deactivation ceases the process. Taking in consideration that atherosclerosis is an inflammatory process and cellular senescence is an emerging cardiovascular risk factor, these new data may be of great importance, especially for chronic kidney disease patients who suffer from increased cardiovascular disease morbidity.

Copyright $\odot 2009$ S. Karger AG, Basel
\end{abstract}

Cellular senescence, a process similar to apoptosis, induces irreversible growth arrest. Cells remain viable but display characteristic changes in their morphology, physiology and gene expression, and are unable to divide [1] While senescence usually occurs after an extensive number of cell divisions (replicative senescence), it also ap- pears prematurely, independently of the number of cell divisions, in response to various physiological stresses (oncogene activity, radiation, oxidative stress, DNA damage, etc.) [2].

Until recently, cellular senescence was connected mostly indirectly to inflammation. Microarray analysis showed that senescent fibroblasts demonstrate a strong inflammatory type response [3]. Ageing CD8+ T cells produce increasing amounts of interleukin (IL)- 6 and tumor necrosis factor- $\alpha$ [4]. Finally, in a recent interesting publication it was shown that reactivation of endogenous p53 (a tumor suppressor factor implicated in apoptosis and senescence induction) in p53-deficient tumors induced cellular senescence that was associated with differentiation and upregulation of inflammatory cytokines [5].

Two new studies published in the same issue of Cell have proven an unexpectedly tight link between the process of cellular senescence and an IL-dependent inflammatory network [6, 7]. Two groups of researchers worked on an oncogene-induced model of premature cellular senescence. Kuilman et al. [6] found that IL-6 is a central regulator of an inflammatory network mediating oncogene-induced senescence (OIS) and upon its depletion the network collapses and cells bypass OIS. Specifically, IL-6 was upregulated in cell lines expressing an oncogenic allele of BRAF (cells programmed to enter prematurely in OIS). When IL- 6 or its receptor (IL- 6 receptor) was suppressed, the cells re-enter the cell cycle and proliferate, so bypassing OIS. This effect of IL- 6 was medi-

\section{KARGER \\ Fax +4161306 1234 \\ E-Mail karger@karger.ch}

www.karger.com (c) 2009 S. Karger AG, Basel

0253-5068/09/0281-0012\$26.00/0

Accessible online at:

www.karger.com/bpu
George Tsirpanlis, MD

Amarysias Artemidos 34

Marousi, GR-15124 Athens (Greece)

Tel. +30 210685 4393, Fax +30 2106854393

E-Mail tsipg@ath.forthnet.gr 
ated through the RB tumor suppressor pathway (the second principal pathway of cellular senescence induction, excepting p53). They also found that suppression of IL-8 is similar to the IL- 6 effect [6]. This latter finding was also confirmed by Acosta et al. [7]. With a similar approach they found that overexpression of chemokine receptor CXCR 2 or its ligands IL- 8 and GRO $\alpha /$ Gro-1 induce replicative and premature OIS. This latter induction was dependent on the $\mathrm{p} 53$ pathway. It is worth mentioning that CXCR 2 was regulated by the transcription factor nuclear factor- $\kappa \mathrm{B}(\mathrm{NF}-\kappa \mathrm{B})[7,8]$ (fig. 1).

These new data are shedding light on the process of atherosclerosis, which also affects chronic kidney disease (CKD) patients in whom atherosclerotic cardiovascular disease (CVD) is the leading cause of morbidity and mortality in a large number of cases [9].

Atherosclerosis is recognized as an inflammatory process that is initiated by oxidized LDL or other stimuli in arterial intima $[10,11]$. Vulnerable atheromatous plaque development and rupture has dramatic consequences (e.g. myocardial infarction) $[10,11]$. Recent studies have shown that many CVD risk factors like diabetes, obesity, hypertension, cigarette smoking, etc., are associated with cellular senescence in diverse cell types [12]. Depending on the phase of atherosclerotic plaque development, the senescence phenotype seems to be atherogenic [12]. In concert with inflammation, cellular senescence makes atherosclerotic plaque vulnerable and thus really dangerous $[13,14]$. Finally, in an increasing number of clinical studies, some biomarkers of cellular senescence, especially telomere - the end of eukaryotic cell chromosomes attrition, in circulating leukocyte DNA, correlated with incident or prevalent atherosclerotic CVD [15]. The new biological data emphasize the strong, inflammation-senescence relationship and support the experimental and clinical data mentioned above linking cellular senescence with the inflammatory process of atherosclerosis.

According to a number of recent publications, cellular senescence, at least in circulating monocytes-leukocytes, seems to develop prematurely in CKD patients [12]. Telomere length as well as the activity of telomerase - that protects telomere structure - in circulating cells, are reduced and inversely correlated to renal function in the same patients [16-18]. Furthermore, both senescence biomarkers were found to be associated with the microinflammatory state - and probably with the oxidative stress - which characterizes these patients $[17,19,20]$. Moreover, new data showed that inflammation may be the link between diverse processes like vascular calcification $[21,22]$ or factors (like sialic acid [23]) and CVD in

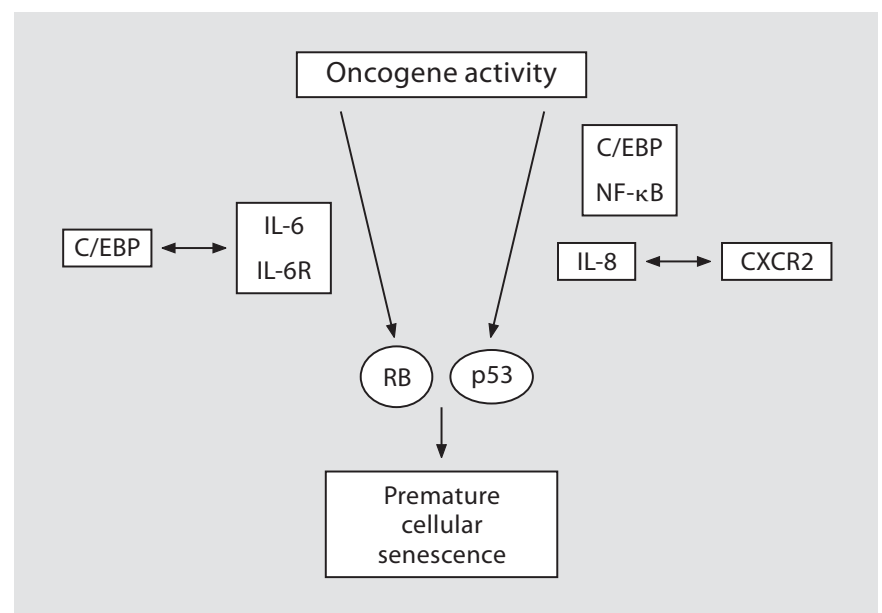

Fig. 1. Induction of premature cellular senescence by oncogene activity via activation of an IL-dependent inflammatory network. The transcription factor C/EBP (CCAA enhancer-binding protein) promotes expression of IL-6. The activity of IL-6 is mediated by IL- 6 receptor (IL-6R). Both molecules promote premature cellular senescence induction via tumor suppressor factor RB activation (left side). Chemokine receptor CXCR2 and its ligand IL8 (and GRO- $\alpha$, not shown) promote cellular senescence via tumor suppressor factor p53. IL-8 upregulation is dependent on C/EBP and NF- $\kappa \mathrm{B}$ transcription factors (right side).

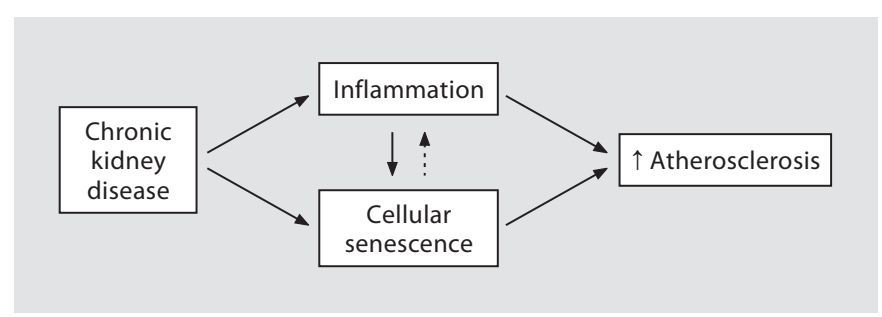

Fig. 2. Inflammation, cellular senescence and atherosclerosis relationships in CKD. Inflammation and cellular senescence are induced in CKD due to multiple, not fully determined factors (oxidant stress seems to be a common causative factor). Both processes seem to be also implicated in the process of atherosclerosis (see text), the main cause of CVD mortality in CKD patients.

CKD patients. In addition, any attempt to alleviate oxidative stress [24,25] or inflammation [26] may be of importance in CVD prevention in the same population.

The above-mentioned new biological data may explain the findings of the cross-sectional studies associating cellular senescence and inflammation in CKD patients. The link seems to be strong. As these new data show, premature senescence induction depends on some 
of the stronger 'players' in the inflammatory cascade at a cellular level, one of which is IL-6. This molecule of note was found to be a significant mortality prognostic factor in CKD patients [26], besides its close relationship with hepatic C-reactive protein production [27]. Combined with the new finding in the field of biology of the relationship between cellular senescence-inflammation and probably atherosclerosis, these data may provide catalytic information for the explanation of the large number of CVD morbidity and mortality cases among CKD patients. Thus, hand-in-hand inflammatory network hy- peractivity, premature cellular senescence induction and early atherosclerosis development may explain the premature biological, vascular aging with dramatic cardiovascular consequences in CKD patients (fig. 2).

\section{Acknowledgment}

The author thanks Christiana Petrihou, MD, for her valuable help in revising the text.

\section{References}

1 Campisi J: Cancer, aging and cellular senescence. In Vivo 2000;14:183-188.

$\checkmark 2$ Ben-Porath I, Weiberg RA: When cells get stressed: an integrative view of cellular senescence. J Clin Invest 2004;113:8-13.

-3 Shelton DN, Chang E, Whittier PS, et al: Microarray analysis of replicative senescence. Curr Biol 1999;9:939-945.

4 Effros RT, Dagarag M, Spaulding C, et al: The role of CD8+ T-cell replicative senescence in human aging. Immunol Rev 2005; 205:147-157.

5 Xue W, Zender L, Miething C, et al: Senescence and tumour clearance is triggered by p53 restoration in murine liver carcinomas. Nature 2007;445:656-660.

6 Kuilman T, Michaloglou C, Vredeveld LC, et al: Oncogene-induced senescence relayed by an interleukin-dependent inflammatory network. Cell 2008;133:1019-1031.

7 Acosta JC, O'Loghlen A, Banito A, et al: Chemokine signaling via the CXCR2 receptor reinforces senescence. Cell 2008;133:10061018.

$\checkmark 8$ Cichowski K, Hahn WC: Unexpected pieces to the senescence puzzle. Cell 2008;133:958961.

-9 Foley RN, Parfrey PS, Sarnak M: Epidemiology of cardiovascular disease in chronic renal failure. Am J Kidney Dis 1998;32(suppl 3):S112-S119.

10 Hansson GK, Robertson AK, SoderbergNaucler C: Inflammation and atherosclerosis. Annu Rev Pathol 2006;1:297-329.

11 Tsirpanlis G: Inflammation in atherosclerosis and other conditions: a response to danger. Kidney Blood Press Res 2005;28:211217.
12 Tsirpanlis G: Cellular senescence, cardiovascular risk, and CKD: a review of established and hypothetical interconnections. Am J Kidney Dis 2008;51:131-144.

13 Matthews C, Gorenne I, Scott S, et al: Vascular smooth muscle cells undergo telomerebased senescence in human atherosclerosis. Effects of telomerase and oxidative stress. Circ Res 2006;99:156-164.

14 Von der Thusen JH, van Vlijmen BJM, Hoeben RC, et al: Inductions of atherosclerotic plaque rupture in apolipoprotein E-/- mice after adenovirus-mediated transfer of p53. Circulation 2002;105:2064-2070.

15 Brouilette SW, Moore JS, McMahon AD, et al: Telomere length, risk of coronary disease, and statin treatment in the West of Scotland Primary Prevention Study: a nested casecontrol study. Lancet 2007;369:107-114.

16 Tsirpanlis G, Chatzipanagiotou S, Boufidou F, et al: Telomerase activity is decreased in peripheral blood mononuclear cells of hemodialysis patients. Am J Nephrol 2006;26: 91-96.

17 Carrero JJ, Stenvinkel P, Fellstrom B, et al: Telomere attrition is associated with inflammation, low fetuin-A levels and high mortality in prevalent haemodialysis patients. J Intern Med 2008;263:302-318.

18 Van der Harst, Wong LSM, de Boer RA, et al: Possible association between telomere length and renal dysfunction in patients with chronic heart failure. Am J Cardiol 2008; 102 : 207-210.

19 Ramirez R, Carracedo J, Soriano S, et al: Stress-induced premature senescence in mononuclear cells from patients on longterm hemodialysis. Am J Kidney Dis 2005; 45:353-359.
20 Tsirpanlis G, Chatzipanagiotou S, Boufidou F, et al: Serum oxidized low-density lipoprotein is inversely correlated to telomerase activity in peripheral blood mononuclear cells of haemodialysis patients. Nephrology 2006; 11:506-509.

21 Dellegrottaglie S, Sanz J, Rajagopalan S: Vascular calcification in patients with chronic kidney disease. Blood Purif 2006;24:56-62.

22 Tsirpanlis G: Is inflammation the link between atherosclerosis and vascular calcification in chronic kidney disease? Blood Purif 2007;25:179-182.

-23 Tseke P, Grapsa E, Stamatelopoulos K, et al: Correlations of sialic acid with markers of inflammation, atherosclerosis and cardiovascular events in hemodialysis patients. Blood Purif 2008;26:261-266.

24 Furuya R, Odamaki M, Kumagai H, et al: Impact of angiotensin II receptor blocker on plasma levels of adiponectin and advanced oxidation protein products in peritoneal dialysis patients. Blood Purif 2006;24:445450.

25 Lim PS, Chen SL, Wu MY, et al: Association of plasma adiponectin levels with oxidative stress in hemodialysis patients. Blood Purif 2007;25:362-369.

26 Pecoits-Filho R, Barany P, Lindholm B, et al: Interleukin- 6 is an independent predictor of mortality in patients starting dialysis treatment. Nephrol Dial Transplant 2002; 17: 1684-1688.

27 Tsirpanlis G: The pattern of inflammation and a potential new clinical meaning and usefulness of C-reactive protein in end-stage renal failure patients. Kidney Blood Press Res 2005;28:55-61. 